\title{
Juglanin alleviates myocardial injury in rats with acute myocardial infarction through modulating
}

\section{MAPK signaling pathway}

\author{
Jing Sun ${ }^{1}$, Lei Song ${ }^{2 *}$ \\ ${ }^{1}$ Department of Cardiac Rehabilitation, Bayannur City Hospital, Bayannur, the Nei Monggol Autonomous Region, China; \\ ${ }^{2}$ Department of Cardiovascular Diseases, Xinhua Hospital Chongming Branch, Shanghai, China
}

*Corresponding author: Lei Song, Department of Cardiovascular Diseases, Xinhua Hospital Chongming Branch, No. 25 Nanmen Gang Street, Chongming District, Shanghai 202150, China. Email: lei_song78@163.com

Received: 28 September 2021; Accepted: 21 October 2021 2021; Published: 12 November 2021

(c) 2021 Codon Publications

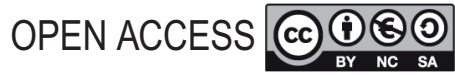

ORIGINAL RESEARCH

\begin{abstract}
The aim of this study was to investigate the protective role of Juglanin in rats suffering from acute myocardial infarction (AMI). Male Sprague-Dawley (SD) mice were used to construct the AMI model. Hematoxylin and Eosin staining was used to observe the morphological changes of cardiomyocytes. Changes in lactate dehydrogenase (LDH), caspase-3 and caspase-9 were measured using commercial kits. Enzyme-linked immunosorbent assay was used to measure the serum level of creatine kinase myocardial band (CK-MB), Interleukin-6 (IL-6), tumor necrosis factor alpha (TNF- $\alpha$ ), IL-10 and IL-1 $\beta$. Protein expression and phosphorylation were determined by Western blotting test. The morphology of cardiomyocytes suffered great changes because of AMI, which included focal myocardial necrosis, severe inflammatory cell infiltration, and myocardial fiber dissolution, disorder, and partial rupture. The morphological changes in cardiomyocytes were significantly ameliorated through treatment with Juglanin $(10 \mathrm{mg} / \mathrm{kg}$ and $30 \mathrm{mg} / \mathrm{kg})$. Increment of serum CK-MB, LDH, IL-6, TNF- $\alpha$, IL-10 and IL-1 $\beta$ was reduced in AMI rats treated with $10-\mathrm{mg} / \mathrm{kg}$ and $30-\mathrm{mg} / \mathrm{kg}$ Juglanin. Cell apoptosis was also inhibited by Juglanin treatment. AMI-induced phosphorylation of p38, extracellular signal-regulated kinase (p-ERK) and c-Jun $\mathrm{N}$-terminal kinase (p-JNK) was suppressed through treatment with Juglanin. This study demonstrated that Juglanin alleviated myocardial injury in rats because of AMI through inactivation of mitogen-activated protein kinase signaling pathway, thus indicating a protective role in rat AMI model.
\end{abstract}

Keywords: Juglanin; myocardial injury; acute myocardial infarction (AMI); MAPK signaling pathway

\section{Introduction}

Acute myocardial infarction (AMI)-induced fatalities account for more than $50 \%$ of cardiovascular deaths (Pollard, 2000). AMI happens if blood supply to the heart is suspended due to thrombus or atherosclerotic plaque in the coronary artery (Boateng and Sanborn, 2013). Many risk factors, such as age, family history, smoking and alcohol intake, have been found to increase incidence of AMI (Boateng and Sanborn, 2013). Current treatment strategies for AMI include immediate reperfusion and revascularization, mainly percutaneous coronary intervention (PCI) and coronary artery bypass grafting (CABG) (Reed et al., 2017). Antithrombotic therapies, such as antiplatelet agents, anticoagulant agents and lipid-lower agents, are used for preventing the recurrence of AMI (Reed et al., 2017).

As the direct target organ of AMI, the heart is injured by ischemia even if the blood supply is recovered by PCI or CABG (Reed et al., 2017). Many signaling pathways are activated due to AMI and contribute to injury (Sanada 
et al., 2011). Activation of $\mathrm{p} 38$ mitogen-activated protein kinase (MAPK) is one of the crucial signaling pathways leading to inflammation of the myocardium after AMI (Meldrum et al., 2005). In response to AMI, proinflammatory cytokines, such as tumor necrosis factor alpha (TNF- $\alpha$ ), interleukin-6 (IL-6) and IL-1 $\beta$, increase to induce myocardial injury (Meldrum et al., 2005). In contrast, anti-inflammatory cytokines, such as IL-10, decrease and the protective effects of AMI are reduced (Ito and Ikeda, 2003). Therefore, reduction of proinflammatory cytokines and growth of anti-inflammatory cytokines are the therapeutic goals to prevent cardiac damage because of AMI.

Juglanin (kaempferol-3-O- $\alpha$-L-arabinofuranoside) is a natural flavonoid extracted from Polygonum aviculare (Chen et al., 2019). Juglanin has demonstrated anti-inflammatory effect by reducing IL-1 $\beta$ in human chondrocytes (Chen et al., 2019). In fructose-induced hepatitis rat model, Juglanin was reported to inhibit the activation of TLR4/MAPK/NF- $\mathrm{KB}$ axis to reduce the production of TNF- $\alpha$, IL- 6 and IL- $1 \beta$, thus demonstrating an anti-inflammatory and protective role in hepatitis (Zhou et al., 2016). Furthermore, Juglanin was also able to reduce the size of infarct and suppress hyperpermeablity of bloodbrain barrier induced by brain ischemia through inhibition of vascular endothelial growth factor (VEGF) and its receptor, VEGF receptor 2 (VEGFR2) signaling pathway (Liu et al., 2020). However, no study has reported the role of Juglanin in cardiac ischemia. Therefore, this study explored the role of Juglanin in AMI and its underlying mechanism.

\section{Methods}

\section{Animal model}

Male Sprague-Dawley (SD) mice (weight: 250-300 g) were purchased from Shanghai Jake Biotechnology Co. Ltd. (Jake Bio, China). The rats were fed with standard animal food and drinking water and kept under standard conditions: 12 -h dark/light cycle at $23 \pm 1^{\circ} \mathrm{C}$ with $50 \pm$ $5 \%$ humidity. All experimental procedures were carried out in compliance with the protocol approved by the Institutional Animal Care and Use Committee of Xinhua Hospital Chongming Branch, Shanghai (Approval No. 201804-032), and were executed conforming to the Care and Use of Laboratory Animals, 8th edition (National Institutes of Health, 2011).

AMI rat model was constructed by ligation of the left anterior descending artery following the prior publication (Wang et al., 2020). SD mice were anesthetized with intraperitoneal injection of $10 \%$ chloral hydrate $(300 \mathrm{mg} /$ kg; Sigma-Aldrich, St. Louis USA). The rat chest was opened at the 3rd and 4th intercostal spaces and the heart was exposed for surgical intervention. A slipknot with 6-0 silk suture was placed at the distal $1 / 3$ of the left anterior descending artery until the cardiac apex became white. The rat chest was closed and penicillin was used to prevent infection. Juglanin (Nakeli, Chengdu, China) was dissolved into the drinking water of rats and treated by intragastric administration.

After the AMI model was successfully constructed, rats were randomly divided into the following four groups ( $\mathrm{n}=8 \mathrm{rats} /$ group) - sham group: rat chest were opened and closed without any further operation or treatment; AMI group: AMI model was constructed and the rats were treated with drinking water by intragastric administration for 14 days; AMI + Jug (10 mg/kg) group: AMI model was constructed and the rats were treated with $10-\mathrm{mg} / \mathrm{kg}$ Juglanin by intragastric administration for 14 days; AMI + Jug (30 mg/kg) group: AMI model was constructed and the rats were treated with $30-\mathrm{mg} / \mathrm{kg}$ Juglanin by intragastric administration for 14 days. After treatment, all rats were sacrificed with an overdose of $10 \%$ chloral hydrate $(500 \mathrm{mg} / \mathrm{kg})$ administered intraperitoneally. The serum and hearts were collected and stored at $-80^{\circ} \mathrm{C}$ for further experiments.

\section{Hematoxylin and eosin (H\&E) staining}

Hematoxylin and Eosin staining was used to examine the histological injury of myocardial tissues (Feldman and Wolfe, 2014). Half of the stored hearts were fixed with $4 \%$ paraformaldehyde (Leagene, Beijing, China) at $4^{\circ} \mathrm{C}$ overnight. The fixed hearts were embedded in paraffin wax and cut into $5-\mu \mathrm{m}$ sections. The sections were then deparaffinized in xylene and dehydrated in graded ethanol. The sections were stained with hematoxylin solution (Abcam, Cambridge, UK) for $15 \mathrm{~min}$ and washed with running water. The sections were further stained with Eosin Y solution (Abcam) for $3 \mathrm{~min}$. The sections were imaged using an inverted microscope (Wumo, Shanghai, China).

\section{TUNEL assay}

The TUNEL assay was used to determine cardiomyocyte apoptosis (Kyrylkova et al., 2012). The TUNEL assay kit was purchased from Beyotime Biotechnology Co. Ltd. (Beyotime, Shanghai, China). The heart sections were obtained as mentioned above, which were then incubated with $0.1 \%$ Triton X-100 (Aladdin, Shanghai, China) and stained with TUNEL staining solution in dark following the manufacturer's instructions. Then the sections were stained with nucleus dye DAPI (Beyotime) and photographed under a fluorescence microscope (Wumo, Shanghai, China). 


\section{Enzyme-linked immunosorbent assay (ELISA)}

Creatine kinase myocardial band (CK-MB), IL-6, TNF- $\alpha$, IL-10 and IL-1 $\beta$ were measured using commercial ELISA kits (R\&D Systems, Minneapolis, USA) according to manufacturer's protocols (Lequin, 2005). Optical density (OD) was recorded at $450 \mathrm{~nm}$ by Varioskan LUX multimode microplate reader (Thermo Fisher, Waltham, USA).

\section{Measurement of lactate dehydrogenase (LDH), Caspase- 3 and Caspase- 9 activity}

Activity of LDH, Caspase- 3 and Caspase- 9 was measured using LDH commercial kits (AmyJet, Wuhan, China), and Caspase- 3 and Caspase-9 fluorometric assay kits according to manufacturer's protocols. Optical density was recorded at $505 \mathrm{~nm}$ by Varioskan LUX multimode microplate reader (Thermo Fisher).

\section{Western blotting test}

Proteins from the hearts of rats were extracted using T-PER ${ }^{\mathrm{m}}$ Tissue Protein Extraction Reagent (Thermo Fisher); $10 \mu \mathrm{g}$ of total proteins was loaded into $10 \%$ sodium dodecyl sulfate-polyacrylamide gel (SDS-PAGE) and separated by electrophoresis. Proteins were transferred from SDS-PAGE to polyvinylidene fluoride (PVDF) membranes (Merck KGaA, Germany). After blockade with 5\% fat-free milk for $2 \mathrm{~h}$ at room temperature, the PVDF membranes were incubated with proper primary antibodies overnight at $4^{\circ} \mathrm{C}$ followed by probing with secondary antibodies for $2 \mathrm{~h}$ at room temperature. The protein band was visualized using ultrahigh sensitivity ECL Substrate Kit (Abcam). Following are the primary antibodies (Abcam) used in the study: p-p38 (ab178867, 1:500 dilution), p38 (ab31828, 1:1,000 dilution), phosphorylated extracellular signal-related kinases (p-ERK; ab201015, 1:1,000 dilution), ERK (ab32537, 1:1,000 dilution), phosphorylated c-Jun N-terminal kinase (p-JNK; ab76572, 1:1,000 dilution), JNK (ab208035, 1:500 dilution) and glyceraldehyde 3-phosphate dehydrogenase (GAPDH; ab8245, 1:5,000 dilution).

\section{Statistical analysis}

Data were analyzed using the statistical software SPSS 17.0 (IBM, USA). All data were presented as mean \pm SD. Statistical differences were analyzed using Scheffe's method of paired comparisons. Statistical significance was defined as $P<0.05$.

\section{Results}

\section{Juglanin alleviated AMI-induced myocardial injury in rats}

No morphological changes were observed in the sham group. The myocardial cells did not demonstrate any obvious degradation and their arrangement was regular and clear. Both myofilament and intercellular space were intact (Figure 1A).

(B)
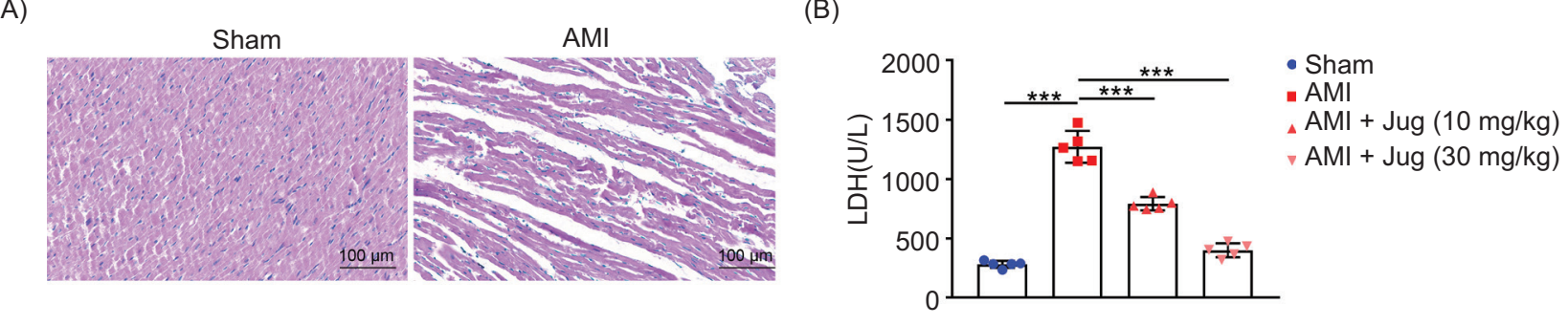

(D)

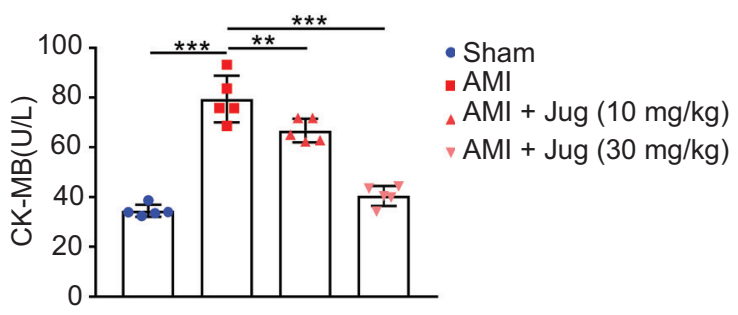

Figure 1. Juglanin alleviated AMI-induced myocardial injury in rats. (A) Morphological changes induced by AMI improved in AMI rats treated with $10-\mathrm{mg} / \mathrm{kg}$ and $30-\mathrm{mg} / \mathrm{kg}$ Juglanin; (B) increment of LDH induced by AMI was inhibited in AMI rats treated with $10-\mathrm{mg} / \mathrm{kg}$ and $30-\mathrm{mg} / \mathrm{kg}$ Juglanin; (C) increment of CK-MB induced by AMI was inhibited in AMI rats treated with 10-mg/kg and $30-\mathrm{mg} / \mathrm{kg}$ Juglanin. ${ }^{*} P<0.01$ versus the Sham or AMl group; ${ }^{* *} P<0.005$ versus the Sham or AMl group. AMl: acute myocardial infarction; Jug: Juglanin; LDH: lactate dehydrogenase; CK-MB: creatine kinase myocardial band. 
In the AMI model group, focal myocardial necrosis was observed in infarct tissues. Myocardial fiber depicted obvious dissolution, disorder and partial rupture. Karyotype fusion and nuclear hemorrhage were observed in some myocardial cells, and dilation of blood vessels was determined in myocardial capillaries. Furthermore, severe inflammatory cell infiltration and myocardial necrosis were observed under the epicardium (Figure 1A).

In the AMI rats treated with $10-\mathrm{mg} / \mathrm{kg}$ and $30-\mathrm{mg} / \mathrm{kg}$ Juglanin groups, loose, edematous and necrotic cardiomyocytes were fewer than those in the AMI model group. The arrangement of myocardial cells was relatively regular in the Juglanin-treated groups. The inflammatory cell infiltration was improved by Juglanin treatment and the morphology of myocardial cells in Juglanin-treated groups was clearer compared with that in the AMI group (Figure 1A).

Lactate dehydrogenase and CK-MB levels were increased in the AMI group compared to the Sham group, and the treatment with Juglaninde inhibited AMI-induced elevation of $\mathrm{LDH}$ in a dose-dependent manner (Figures $1 \mathrm{~B}$ and $1 \mathrm{C}$ ). These results indicated that the morphological changes in myocardial tissue induced by AMI were improved in the AMI model rats treated with $10-\mathrm{mg} / \mathrm{kg}$ and 30-mg/kg Juglanin.

\section{Juglanin prevented inflammatory response in AMI rats}

The IL-6 level in serum was significantly increased postAMI, which was reduced by Juglanin $(10 \mathrm{mg} / \mathrm{kg}$ and
$30 \mathrm{mg} / \mathrm{kg}$ ) treatment (Figure 2A). The TNF- $\alpha$ level in serum of the AMI group was elevated compared to the Sham group (Figure 2B). However, a significant reduction in serum TNF- $\alpha$ was observed in the AMI rats treated with $10-\mathrm{mg} / \mathrm{kg}$ and $30-\mathrm{mg} / \mathrm{kg}$ Juglanin (Figure 2B). The IL-10 level in serum was significantly decreased after AMI, which was reversed by Juglanin $(10 \mathrm{mg} / \mathrm{kg}$ and 30 $\mathrm{mg} / \mathrm{kg}$ ) treatment (Figure $2 \mathrm{C}$ ). In the AMI group, serum IL-1 $\beta$ was elevated compared to that in the Sham group (Figure 2D). A significant reduction of serum IL-1 $\beta$ was observed in AMI rats treated with $10-\mathrm{mg} / \mathrm{kg}$ and $30-\mathrm{mg} / \mathrm{kg}$ Juglanin compared to that in the AMI group (Figure 2D); this demonstrates that Juglanin inhibited inflammatory response and enhanced anti-inflammatory response in AMI rats.

\section{Juglanin inhibited myocardial cell apoptosis in AMI rats}

The number of TUNEL-positive cells increased after AMI; however, treatment of AMI rats with Juglanin (10 $\mathrm{mg} / \mathrm{kg}$ and $30 \mathrm{mg} / \mathrm{kg}$ ) reduced the number of TUNEL-positive cells in myocardial infarcted tissues (Figure 3). Caspase-3 activity significantly increased in rat tissues after AMI, but decreased by Juglanin (10 mg/ $\mathrm{kg}$ and $30 \mathrm{mg} / \mathrm{kg}$ ) treatment (Figure 4A). In the AMI group, Caspase- 9 activity increased compared with that in the Sham group (Figure 4B). However, a significant reduction of Caspase- 9 activity was observed in AMI rats treated with $10-\mathrm{mg} / \mathrm{kg}$ and $30-\mathrm{mg} / \mathrm{kg}$ Juglanin (Figure $4 \mathrm{~B})$, thus demonstrating that Juglanin prevented cell apoptosis after AMI in rats.
(A)

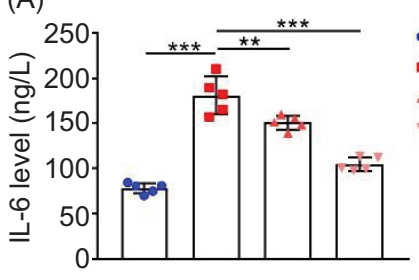

(C)

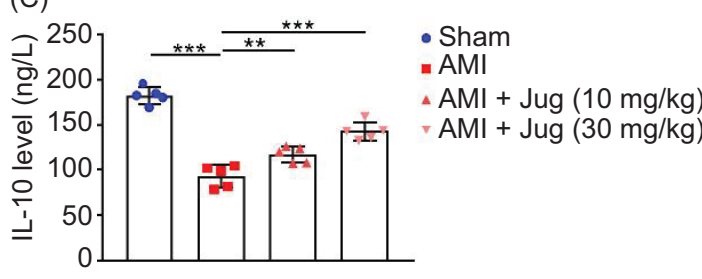

(B)

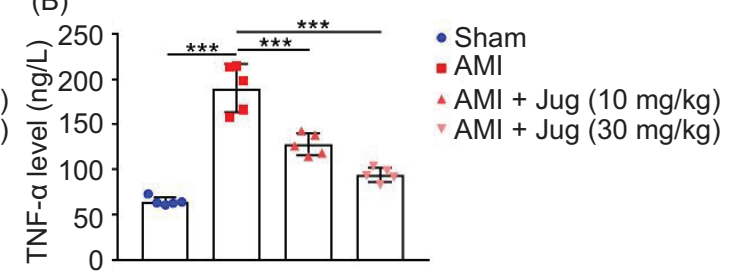

(D)

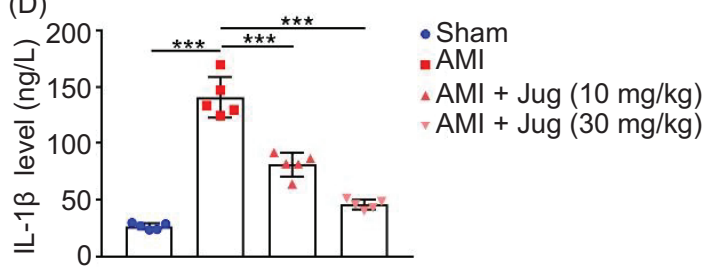

Figure 2. Juglanin inhibited inflammatory response in AMI rats. (A) Increment of serum IL-6 was inhibited by 10-mg/kg and $30-\mathrm{mg} / \mathrm{kg}$ Juglanin in AMI rats; (B) increment of serum TNF- $\alpha$ was inhibited by $10-\mathrm{mg} / \mathrm{kg}$ and $30-\mathrm{mg} / \mathrm{kg}$ Juglanin in AMI rats; (C) reduction of serum IL-10 was inhibited by $10-\mathrm{mg} / \mathrm{kg}$ and $30-\mathrm{mg} / \mathrm{kg}$ Juglanin in AMI rats; (D) increment of serum IL-1及 was inhibited by $10-\mathrm{mg} / \mathrm{kg}$ and $30-\mathrm{mg} / \mathrm{kg}$ Juglanin in AMI rats. ${ }^{* * *} P<0.005$ versus the Sham or AMI group. IL: interleukin; TNF- $\alpha$ : tumor necrosis factor alpha. 


\section{Juglanin regulated MAPK signaling pathways}

The phosphorylation of p38 MAPK was induced in AMI rats, which was prevented by $10-\mathrm{mg} / \mathrm{kg}$ and $30-\mathrm{mg} / \mathrm{kg}$ Juglanin (Figure 5). AMI enhanced the phosphorylation of ERK (p-ERK) in rats, but treatment with $10-\mathrm{mg} / \mathrm{kg}$ and $30-\mathrm{mg} / \mathrm{kg}$ Juglanin suppressed the upregulation of $\mathrm{p}$-ERK (Figure 5). The phosphorylated JNK (p-JNK) was upregulated in AMI rats, but treatment with Juglanin $(10 \mathrm{mg} /$ $\mathrm{kg}$ and $30 \mathrm{mg} / \mathrm{kg}$ ) inhibited the phosphorylation of JNK in AMI rats (Figure 5), suggesting that Juglanin inhibited the activation of MAPK signaling pathway.

\section{Discussion}

With the introduction of PCI and CABG, the mortality because of AMI has greatly reduced and the clinical use of antithrombotic agents has significantly prolonged the survival of AMI patients (Reed et al. 2017), although burden of the disease is still very high (Edupuganti and Ganga, 2019). Thus, effective supplemental treatment must be identified on the basis of standard care to improve patient prognosis. In the present study, Juglanin altered changes in cardiomyocytes after AMI and reduced the increase of CK-MB and LDH induced by AMI. Juglanin inhibited inflammatory response and repressed AMI-induced cardiomyocyte apoptosis by inhibiting the activation of MAPK signaling pathway, thus demonstrating its anti-inflammatory and protective role in AMI-induced myocardial injury.

CK-MB and LDH were specific markers of AMI (Mechanic et al., 2021). Data of the present study manifested that Juglanin inhibited the elevation of CK-MB and $\mathrm{LDH}$ induced by AMI, thus demonstrating its protective role in AMI. Myocardial necrosis and cardiomyocyte apoptosis are key features of AMI (Mechanic et al., 2021). Therefore, prevention of cardiomyocyte apoptosis could prevent cardiac dysfunction after AMI. In this study, TUNEL-positive cells and Caspase-3 activity decreased in AMI rats treated with Juglanin, thereby proving that Juglanin suppressed the AMI-induced cardiac damage. Altogether, treatment with Juglanin alleviated cardiac dysfunction in AMI rats.

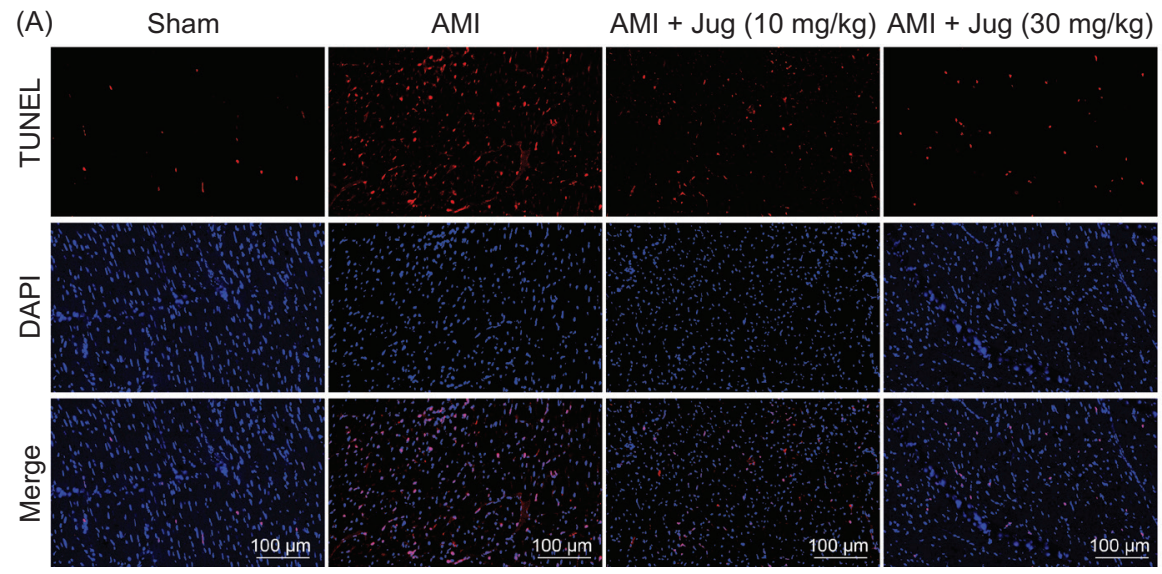

(B)

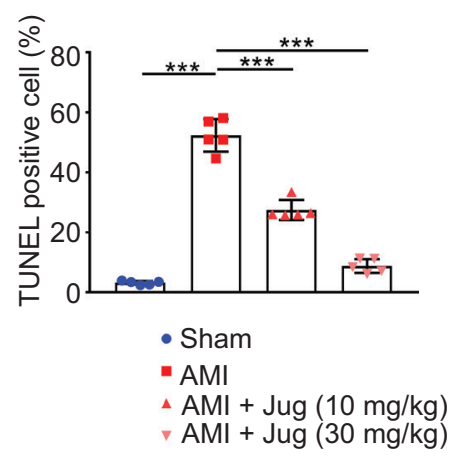

Figure 3. Juglanin inhibited myocardial apoptosis in AMI rats. Juglanin (10 mg/kg and $30 \mathrm{mg} / \mathrm{kg})$ reduced the number of TUNEL-positive cells in AMI rats. ${ }^{* * *} P<0.005$ versus the Sham or AMI group.
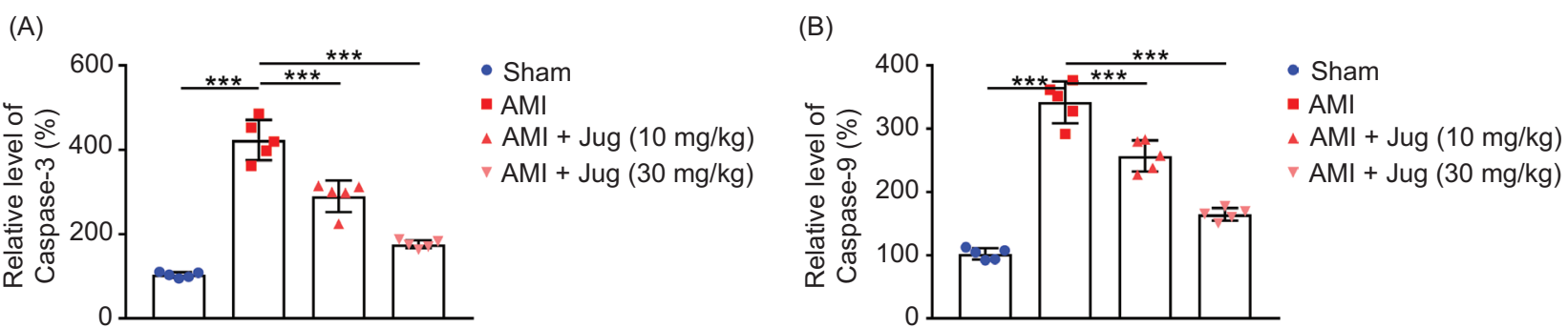

Figure 4. Juglanin reduced the activity of Caspase-3 and Caspase-9. (A) Juglanin (10 mg/kg and $30 \mathrm{mg} / \mathrm{kg}$ ) reduced Caspase-3 activity in AMI rats; (B) Juglanin (10 mg/kg and $30 \mathrm{mg} / \mathrm{kg}$ ) reduced Caspase- 9 activity in AMI rats. ${ }^{* * *} P<0.005$ versus the Sham or AMI group. 


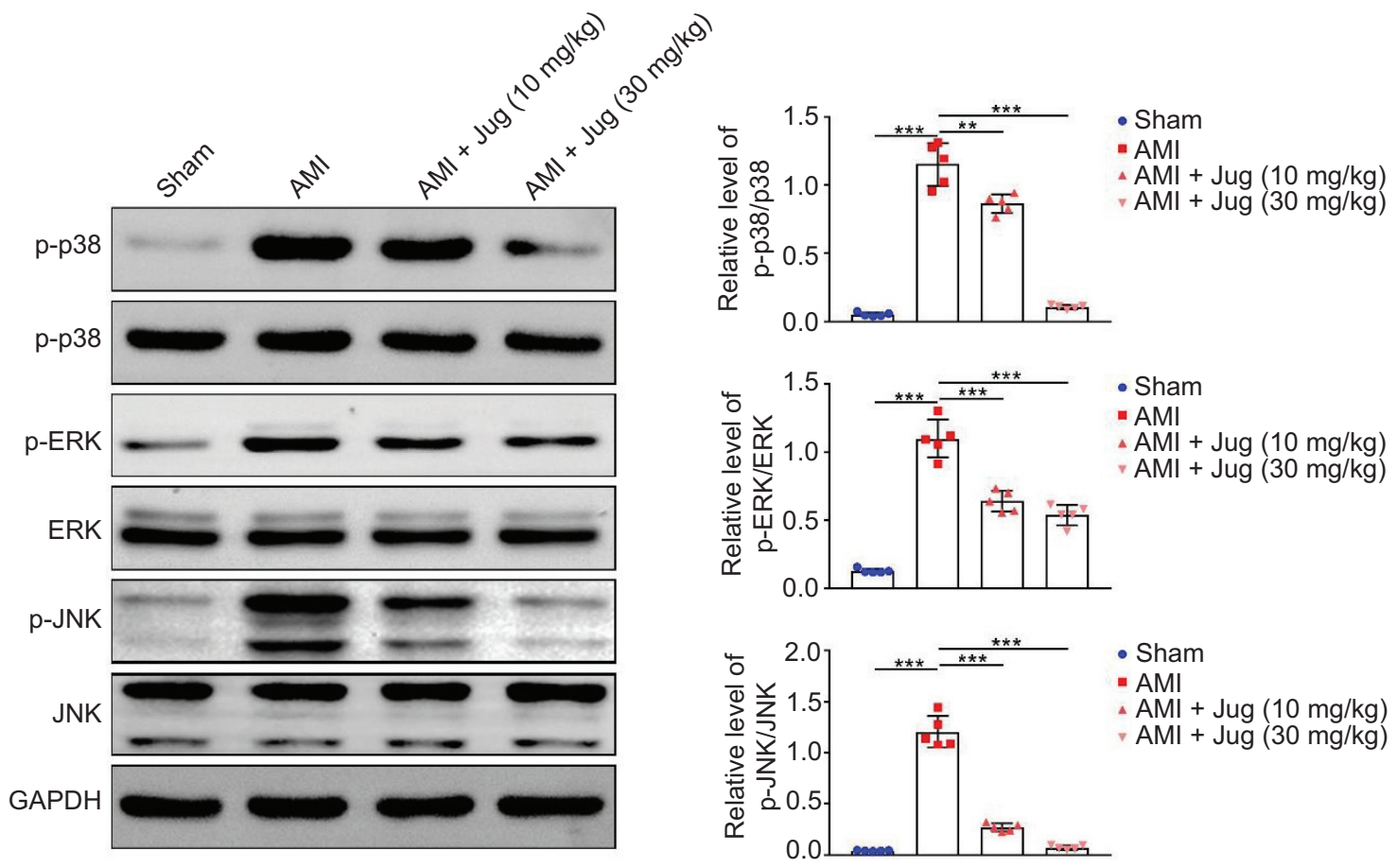

Figure 5. Juglanin regulated MAPK signaling pathways. The phosphorylation of p38, EKR and JNK induced by AMI was down-regulated in AMI rats treated with $10-\mathrm{mg} / \mathrm{kg}$ and $30-\mathrm{mg} / \mathrm{kg}$ Juglanin. ${ }^{* *} P<0.01$ versus the Sham or AMI group; ${ }^{* * *} P<0.005$ versus the Sham or AMI group.

The onset of AMI initiates pro-inflammatory response, resulting in the production of proinflammatory cytokines, leading to cardiomyocyte apoptosis (Ong et al., 2018). In this study, production of proinflammatory cytokines, such as IL-6, TNF- $\alpha$ and IL-1 $\beta$, was significantly increased after AMI, but was inhibited by Juglanin treatment. In response to proinflammatory response, anti-inflammatory process was activated to repair the cardiac damage induced by AMI. Production of anti-inflammatory cytokines, such as IL-10, decreased after AMI, but was reversed by Juglanin by increasing serum IL-10 level in a dose-dependent manner, thus enhancing anti-inflammatory response in AMI rats. Therefore, Juglanin played an anti-inflammatory role in AMI rats, which was consistent with the reports of previous studies (Zhou et al., 2016).

MAPK signaling pathway is a key regulator of ischemia (Sun and Nan, 2016). Once activated, the downstream proteins, including $\mathrm{p} 38$, JNK and EKR, were phosphorylated and participated in regulating cell proliferation, apoptosis and survival (Sun and Nan, 2016). In this study, the phosphorylation of p38, JNK and EKR was upregulated in AMI rats, implying the activation of MAPK signaling pathway because of AMI. Treatment with Juglanin repressed the phosphorylation of p38, JNK and EKR, suggesting that it inhibited the activation of MAPK signaling pathway. Moreover, it is revealed that MAPK signaling pathway is associated with the initiation of inflammation process (Ni, 2020; Yeung, 2018). Overall, Juglanin inhibited the inflammatory response induced by AMI in rats through inactivation of MAPK signaling pathway.

\section{Conclusion}

This study established that Juglanin inhibited myocardial injury and cardiomyocyte apoptosis, and repressed the inflammatory response after AMI through inactivating MAPK signaling pathway. To our knowledge, this is the first study to discuss the protective role of Juglanin in an AMI rat model. Thus, these findings provided a new insight to prevent cardiac dysfunction after AMI. Juglanin could be a nutrient supplement to repair cardiac damage induced by AMI.

\section{Availability of Data and Materials}

All data generated or analyzed during this study are included in the published article.

\section{Competing Interests}

The authors state that there are no conflicts of interest to disclose. 


\section{Author Contribution}

Jing Sun designed the study and supervised data collection. Lei Song analyzed and interpreted the data. Both authors prepared, reviewed and approved the manuscript for publication.

\section{References}

Boateng, S. and Sanborn, T., 2013. Acute myocardial infarction. Disease-a-Month 59(3): 83-96. https://doi.org/10.1016/j. disamonth.2012.12.004

Chen, X. et al., 2019. Juglanin inhibits IL-1 $\beta$-induced inflammation in human chondrocytes. Artificial Cells, Nanomedicine, and Biotechnology 47(1): 3614-3620. https://doi.org/10.1080/21691 401.2019.1657877

Edupuganti, M.M. and Ganga, V., 2019. Acute myocardial infarction in pregnancy: current diagnosis and management approaches. Indian Heart Journal 71(5): 367-374. https://doi.org/10.1016/j. ihj.2019.12.003

Feldman, A.T. and Wolfe, D., 2014. Tissue processing and hematoxylin and eosin staining. Methods in Molecular Biology 1180: 31-43. https://doi.org/10.1007/978-1-4939-1050-2_3

Ito, T. and Ikeda, U., 2003. Inflammatory cytokines and cardiovascular disease. Current Drug Targets Inflammation and Allergy 2(3): 257-265. https://doi.org/10.2174/1568010033484106

Kyrylkova, K. et al., 2012. Detection of apoptosis by TUNEL assay. Methods in Molecular Biology 887: 41-47. https://doi. org/10.1007/978-1-61779-860-3_5

Lequin, R.M., 2005. Enzyme immunoassay (EIA)/enzyme-linked immunosorbent assay (ELISA). Clinical Chemistry 51(12): 2415-2418. https://doi.org/10.1373/clinchem.2005.051532

Liu, J. et al., 2020. The protective effects of juglanin in cerebral ischemia reduce blood-brain barrier permeability via inhibition of VEGF/VEGFR2 signaling. Drug Design, Development and Therapy 14: 3165-3175. https://doi.org/10.2147/DDDT.S250904

Mechanic, O.J., Gavin, M. and Grossman, S.A., 2021. Acute myocardial InfarctionStatPearls Publishing, Treasure Island, FL.

Meldrum, D.R. et al., 2005. Intracellular signaling mechanisms of sex hormones in acute myocardial inflammation and injury. Frontiers in Bioscience 10: 1835-1867. https://doi. org/10.2741/1665
National Institutes of Health, 2011. National Research Council (US) committee for the update of the guide for the care and use of laboratory animals. In: Guide for the care and use of laboratory animals, 8th edition. The National Academies collection. National Academy of Sciences, Washington, DC.

Ni, W.W. et al., 2020. Modulation effect of Lactobacillus acidophilus KLDS 1.0738 on gut microbiota and TLR4 expression in $\beta$-lactoglobulin-induced allergic mice model. Allergologia et Immunopathologia 48(2): 149-157. https://doi.org/10.1016/j. aller.2019.06.002

Ong, S.B. et al., 2018. Inflammation following acute myocardial infarction: multiple players, dynamic roles, and novel therapeutic opportunities. Pharmacology and Therapeutics 186: 73-87. https://doi.org/10.1016/j.pharmthera.2018.01.001

Pollard, T.J., 2000. The acute myocardial infarction. Primary Care 27(3): 631-649; vi. https://doi.org/10.1016/S0095-4543(05)70167-6

Reed, G.W., Rossi, J.E. and Cannon, C.P., 2017. Acute myocardial infarction. Lancet 389(10065): 197-210. https://doi.org/10.1016/ S0140-6736(16)30677-8

Sanada, S., Komuro, I. and Kitakaze, M., 2011. Pathophysiology of myocardial reperfusion injury: preconditioning, postconditioning, and translational aspects of protective measures. American Journal of Physiology, Heart and Circulatory Physiology 301(5): H1723-H1741. https://doi.org/10.1152/ajpheart.00553.2011

Sun, J. and Nan, G., 2016. The mitogen-activated protein kinase (MAPK) signaling pathway as a discovery target in stroke. Journal of Molecular Neuroscience 59(1): 90-98. https://doi. org/10.1007/s12031-016-0717-8

Wang, Y. et al., 2020. Influence of dl-3-N-butylphthalide on infarction size in rats with acute myocardial infarction. International Journal of Clinical and Experimental Pathology 13(7): 17071711. PMID: 32782693; PMCID: PMC7414500.

Yeung, Y.T. et al., 2018. Signaling pathways in inflammation and anti-inflammatory therapies. Current Pharmaceutical Design 24(14): 1449-1484. https://doi.org/10.2174/1381612824666180 327165604

Zhou, G.Y. et al., 2016. The protective effect of juglanin on fructose-induced hepatitis by inhibiting inflammation and apoptosis through TLR4 and JAK2/STAT3 signaling pathways in fructose-fed rats. Biomédecine \& Pharmacothérapie 81: 318-328. https://doi.org/10.1016/j.biopha.2016.04.013 